\title{
Dietary and Demographical Risk Factors for Oesophageal Squamous Cell Carcinoma in the Eastern Anatolian Region of Turkey Where Upper Gastrointestinal Cancers are Endemic
}

\author{
Timur Koca ${ }^{1 *}$, Deniz Arslan ${ }^{2}$, Hamit Basaran ${ }^{1}$, Arda Kaymak Cerkesli ${ }^{1}$, Didem \\ Tastekin $^{3}$, Duygu Sezen ${ }^{1}$, Ozlem Koca ${ }^{4}$, Dogan Nasir Binici ${ }^{5}$, Cumhur İbrahim \\ Bassorgun $^{6}$, Mustafa Ozdogan ${ }^{7}$
}

\begin{abstract}
Background: Oesophageal squamous cell carcinoma (ESCC) is endemic in the Eastern Anatolian region of Turkey. The present study was performed to identify risk factors for ESCC that specifically reflect the demography and nutritional habits of individuals living in this region. Materials and Methods: The following parameters were compared in 208 ESCC patients and 200 control individuals in the Eastern Anatolian region: age, sex, place of living, socioeconomic level, education level, smoking, alcohol intake, nutritional habits, and food preservation methods. Results: The mean age of ESCC patients was 56.2 years, and $87(41.8 \%)$ were 65 years-old or older. The ratio of women to men in the patient group was 1.39/1. ESCC patients consumed significantly less fruit and yellow or green vegetables and more hot black tea, 'boiled yellow butter', and mouldy cheese than did control individuals. Residence in rural areas, smoking, and cooking food by burning animal manure were also significantly associated with ESCC. Conclusions: The consumption of boiled yellow butter and mouldy cheese, which are specific to the Eastern Anatolian region, and the use of animal manure for food preparation were identified as risk factors in this region. Further studies are required to potentially identify the carcinogenic substances that promote the development of ESCC in this region.
\end{abstract}

Keywords: Oesophageal squamous cell carcinoma - Turkey - Eastern Anatolia - risk factors

Asian Pac J Cancer Prev, 16 (5), 1913-1917

\section{Introduction}

Oesophageal cancer is the sixth most common cause of cancer-related death (Sharma et al., 2014). Its five-year survival rate is only 10 to $17 \%$ (Enzinger and Mayer, 2003; Sant et al., 2003). It is more common in men than women, and its incidence increases with age (Blot, 1994; Jamel et al., 2009). There are two types of oesophageal cancer, oesophageal squamous cell carcinoma (ESCC), the incidence of which has slightly decreased, and adenocarcinoma, the incidence of which has increased more than $400 \%$ in recent years (Incarbone et al., 2000; Hajmanoochehri et al., 2013; Dubecz et al., 2014).

Although the aetiopathogenesis of oesophageal cancer is incompletely understood, it is known that various risk factors, especially dietary habits, contribute to its development (De Stefani et al., 2014). Risk factors for ESCC identified in retrospective studies include smoking, consumption of alcohol, red meat, and hot drinks, poor oral hygiene, insufficient consumption of vegetables and fruit, low socioeconomic level, genetics, conditions such as Plummer-Vinson/Patterson-Kelly syndrome and Coeliac disease, and mediastinal radiation (Weng et al., 2012; Andrici and Eslick, 2013; Amani et al., 2013; Tang et al., 2013; Jung et al., 2014). In contrast to ESCC, the risk factors for adenocarcinoma are not very clear but may include oesophageal reflux, smoking, obesity, nitrosamine-containing diets, and high-fat, low-protein, high-calorie diets (Veugelers et al., 2006; Lee., 2012; Kroep et al., 2014).

In certain parts of the world, incidences of some cancers are higher than in the others, and one such region is the Eastern Anatolian region of Turkey, where upper gastrointestinal tumours such as ESCCs are endemic (Uyanikoglu et al., 2011). The present study was performed to identify the risk factors for ESCC that specifically reflect the demography and nutritional habits of individuals living in this region.

${ }^{1}$ Department of Radiation Oncology, ${ }^{2}$ Department of Medical Oncology, ${ }^{5}$ Department of Internal Medicine, Regional Training and Research Hospital, ${ }^{4}$ Department of Microbiology, Nenehatun Gynecology and Obstetric Hospital, Erzurum, ${ }^{3}$ Department of Medical Oncology, Oncology Institute, Medical Faculty, Istanbul University, İstanbul, ${ }^{6}$ Department of Pathology, Faculty of Medicine, Akdeniz University, ${ }^{7}$ Department of Medical Oncology, Medstar Hospital, Antalya, Turkey *For correspondence: timurkoca3@gmail.com 


\section{Materials and Methods}

The present study included 208 ESCC patients, all of whom presented at the medical and radiation oncology clinics at the Erzurum Regional Training and Research Hospital between January 2008 and March 2014. The control group consisted of 200 patients or relatives of patients in other clinics at this hospital who did not have cancer or gastrointestinal problems. All members of the study population resided in the Eastern Anatolian region of Turkey, which is where our hospital is located.

The control and patient groups were compared for age, sex, place of living, socioeconomic level (income), education level, cigarette smoking, alcohol intake, nutritional habits, and food storage methods (Table 1). Income was based on the gross national product reported for 2007 by the World Bank. Incomes of \$9353,705 per year signified low socioeconomic status, and incomes greater than $\$ 3,706$ per year signified medium to high status (Dogan et al., 2011). Fruit and yellow or green vegetable consumption was scored as daily, once a week, 1-3 times a month, or once a month or less, which corresponded to scores of $3,2,1$, and 0 , respectively. Alcohol consumption was categorised as regular consumption or no consumption. Smoking was categorised as heavy (one or more packs of cigarettes per day), light (less than one pack per day), or none (nonsmoker). Hot black tea consumption was categorised as up to 6 cups per day or more than 6 cups per day. Subjects were asked whether they bit small pieces of sugar before each tea swallow, regionally named as "kitlama", a habit known as 'drinking tea with a lump of sugar in the mouth'. They were also asked whether they cooked food by burning animal manure, consumed mouldy cheese or herb cheese, used refrigeration, or used 'boiled yellow butter' for at least 5 years. Although food storage methods have improved with advances in technology, some people living in this region, mainly in rural areas, prepare boiled yellow

Table 1. Patient Characteristics

\begin{tabular}{|c|c|c|c|c|c|c|}
\hline \multirow[t]{2}{*}{ Characteristic } & & \multicolumn{2}{|c|}{ Patient group } & \multicolumn{2}{|c|}{ Control group } & \multirow[t]{2}{*}{$\mathrm{p}$ value } \\
\hline & & Number & Percent & Number & Percent & \\
\hline \multirow[t]{2}{*}{ Age (years) } & $<65$ & 121 & 58.2 & 148 & 74.0 & \\
\hline & $\geq 65$ & 87 & 41.8 & 52 & 26.0 & \\
\hline \multirow[t]{2}{*}{ Sex } & Female & 116 & 55.8 & 102 & 51.0 & \\
\hline & Male & 92 & 44.2 & 98 & 49.0 & \\
\hline \multirow[t]{2}{*}{ Residential area } & Rural & 91 & 43.8 & 40 & 20.0 & \\
\hline & Urban & 117 & 56.2 & 160 & 80.0 & $<0.001$ \\
\hline \multirow[t]{2}{*}{ Socioeconomic status } & Low & 159 & 76.4 & 137 & 68.5 & 0.077 \\
\hline & High or medium & 49 & 23.6 & 63 & 21.5 & \\
\hline \multirow[t]{4}{*}{ Educational status } & University & 17 & 8.2 & 32 & 16.0 & $X^{2}=6.116$ \\
\hline & Medium or high school & 39 & 18.8 & 33 & 16.5 & 0.106 \\
\hline & Elementary school & 118 & 56.7 & 102 & 51.0 & \\
\hline & No education & 34 & 16.3 & 33 & 16.5 & \\
\hline \multirow[t]{4}{*}{ Fruit consumption $^{\mathrm{a}}$} & 3 & 21 & 10.1 & 58 & 29.0 & $\mathrm{X}^{2}=40.800$ \\
\hline & 2 & 44 & 21.2 & 62 & 31.0 & $<0.001$ \\
\hline & 1 & 92 & 44.2 & 42 & 21.0 & \\
\hline & 0 & 51 & 24.5 & 38 & 19.0 & \\
\hline \multirow{4}{*}{$\begin{array}{l}\text { Yellow or green vegetable } \\
\text { consumption }^{\mathrm{a}}\end{array}$} & 3 & 38 & 18.3 & 87 & 43.5 & $\mathrm{X}^{2}=65.136$ \\
\hline & 2 & 46 & 22.1 & 71 & 35.5 & 0.000 \\
\hline & 1 & 102 & 49.0 & 33 & 16.5 & \\
\hline & 0 & 22 & 10.6 & 9 & 4.5 & \\
\hline \multirow[t]{2}{*}{ Alcohol use } & Yes & 66 & 31.7 & 51 & 25.5 & 0.189 \\
\hline & No & 142 & 68.3 & 149 & 74.5 & \\
\hline \multirow[t]{3}{*}{ Tobacco use } & Heavy smoker & 61 & 29.3 & 84 & 42.0 & $X^{2}=7.629$ \\
\hline & Light smoker & 35 & 16.8 & 32 & 16.0 & 0.022 \\
\hline & Non-smoker & 112 & 53.8 & 84 & 42.0 & \\
\hline \multirow[t]{2}{*}{ Tea consumption per day } & Up to six cups & 93 & 44.7 & 68 & 34.0 & 0.033 \\
\hline & More than six cups & 115 & 55.3 & 132 & 66.0 & \\
\hline \multirow{4}{*}{$\begin{array}{l}\text { Drinking tea with a lump of } \\
\text { sugar in the mouth } \\
\text { Boiled butter usage }^{\mathrm{b}}\end{array}$} & Yes & 97 & 46.6 & 108 & 54.0 & 0.140 \\
\hline & No & 111 & 53.4 & 92 & 46.0 & \\
\hline & Yes & 77 & 37.0 & 23 & 11.5 & $<0.001$ \\
\hline & No & 131 & 63.0 & 177 & 88.5 & \\
\hline \multirow{2}{*}{$\begin{array}{l}\text { Food cooked by burning } \\
\text { animal manure }\end{array}$} & Yes & 163 & 78.4 & 116 & 58.0 & $<0.001$ \\
\hline & No & 45 & 21.6 & 84 & 42.0 & \\
\hline \multirow[t]{2}{*}{ Mouldy cheese consumption } & Yes & 161 & 77.4 & 118 & 59.0 & $<0.001$ \\
\hline & No & 47 & 22.6 & 82 & 41.0 & \\
\hline \multirow[t]{2}{*}{ Herbed cheese consumption } & Yes & 53 & 25.5 & 36 & 18.0 & 0.073 \\
\hline & No & 155 & 74.5 & 164 & 82.0 & \\
\hline \multirow[t]{2}{*}{ Own a refrigerator } & Yes & 178 & 85.6 & 182 & 91.0 & 0.094 \\
\hline & No & 30 & 14.4 & 18 & 9.0 & \\
\hline
\end{tabular}

*a Yellow or green vegetable and fruit consumption scores: 3 , orderly daily consumption; 2 , once a week; 1, 1-3 times a month; 0 , once a month or

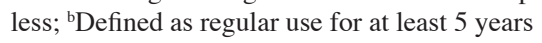


Risk Factors for Oesophageal SCC in the Eastern Anatolia in Turkey Where Upper Gastrointestinal Cancers are Endemic

butter for storage, which does not require refrigeration, by boiling and then cooling sheep grease oil. People living in this region asked whether they used boiled yellow butter for cooking at least five years in their life.

Both patient and control groups are interrogated by the same researchers of the study. The statistical analyses were performed by Chi-square and Fisher's exact test.

\section{Results}

The ESCC patient group in our study contained 116 women (55.8\%) and 92 men $(44.2 \%)$ with a mean age of 56.2 years (median age, 55 years; age range, $30-88$ years) (Table 1). The control group contained 102 women $(51 \%)$ and 98 men $(49 \%)$ with a mean age of 52 years (median age, 51 years; age range, 28-91 years). The number of patients 65 years of age or younger was 121 (58.2\%). Therefore, the incidence of oesophageal cancer peaked in the sixth decade, and the female/male ratio in the patient group was $1.39 / 1$.

The hospital where our study was performed is a regional reference hospital and as such receives patients from all segments of the local population. The socioeconomic and education levels in the rural parts of the Eastern Anatolian region are much lower than in the more developed regions of Turkey. In the patient and control groups, $43.8 \%$ and $20 \%$ were from rural areas, respectively. ESCC was diagnosed more often in patients from rural areas than from urban areas $(\mathrm{p}<0.001)$.

The patient and control groups both consisted primarily of low-income individuals $(76.4 \%$ and $68.5 \%$, respectively). There was no significant difference in socioeconomic status between the two groups $(\mathrm{p}=0.077)$. There was also no significant difference in education level $\left(\mathrm{X}^{2}=6.116, \mathrm{p}=0.106\right)$.

Fruit consumption was significantly lower in the patient group than the control group $\left(\mathrm{X}^{2}=40.800\right.$, $\mathrm{p}<0.001)$, as was yellow or green vegetable consumption $\left(\mathrm{X}^{2}=65.136, \mathrm{p}<0.001\right)$. Smoking $\left(\mathrm{X}^{2}=7.629, \mathrm{p}=0.022\right)$, black tea drinking $(\mathrm{p}=0.033)$, and consumption of boiled butter for 5 or more years $(\mathrm{p}<0.001)$ were significantly higher in the patient group than the control group. There were no significant difference in drinking tea with a lump of sugar in the mouth $(\mathrm{p}=0.14)$ or alcohol consumption $(\mathrm{p}=0.189)$ between the groups.

Particularly in rural areas, use of animal manure as a fuel source for cooking food and consumption of mouldy cheese were significantly associated with ESCC (both $\mathrm{p}$ values $<0.001$ ). However, there was no difference in consumption of herbed cheese, which is specific to the Eastern Anatolian region $(\mathrm{p}=0.073)$, or refrigerator use $(p=0.094)$ between the patient and control groups $(\mathrm{p}=0.073)$.

\section{Discussion}

The ESCC subtype of oesophageal cancer generally occurs in developing countries, whereas the adenocarcinoma subtype is more common in developed countries (Mao et al., 2011; Liu et al., 2013). ESCC is especially endemic in the Eastern Anatolian region of Turkey, as well as some parts of Iran, Afghanistan, Turkmenistan, Kyrgyzstan, Uzbekistan, India, China, and Latin America (Moore et al., 2010; Uyanikoglu et al., 2011; Mosavi-Jarrahi et al., 2013; Tang et al., 2013; De Stefani et al., 2014). In the present study, we compared the demographic features and nutritional habits of 208 ESCC patients in the Eastern Anatolian region with those of a control group, and we evaluated the results of our study in light of the current literature.

The median age of patients with for oesophageal cancer is 67 years (Hajmanoochehri et al., 2013). Its incidence increases with age, and it is 22.3 times higher in individuals 65 years of age or older (Blot, 1994). It is 3.8 times more frequent in men than in women (Jemal et al., 2009). ESCC incidence in our study was the highest in patients in their sixth decade of life. More than half of these patients were younger than 65 years of age and most of them were female.

In the United States of America, oesophageal cancer is relatively common in African-American men living in cities rather than rural areas. According to one report, its incidence among African-American men in Washington D. C. was 28.6 per 100,000 (Pottern et al., 1981). A largescale study reported that low socioeconomic level was related to ESCC (Gammon et al., 1997). In our study, ESCC was associated with rural populations but not with socioeconomic or education level.

Dietary habits, food storage and cooking methods, and human papilloma virus infection are involved in ESCC aetiology. Excessive consumption of red meat increases the risk of ESCC, whereas consumption of chicken, fish, and offal such as liver reduces risk. Vitamins A, C, and $\mathrm{E}$ and minerals such as riboflavin, zinc, selenium, and molybdenum decrease the risk of ESCC, which is prevalent in regions where their intake is reduced. Consumption of fresh fruit and vegetables also reduces the risk of ESCC, and fruit rich in vitamin $\mathrm{C}$ is especially protective against ESCC. Inadequate consumption of fresh fruit and vegetables increases sensitivity to exogenous carcinogens, which facilitates ESCC development. It is believed that $\mathrm{N}$-nitrosamines are the most powerful carcinogens associated with oesophageal cancer development. N-nitroso compounds and their precursors (nitrates and nitrites) are commonly present in canned fish and salted vegetables. In some regions, low levels of molybdenum in the soil result in high levels of nitrates and nitrites in local crops. Citrus fruits and vitamin $\mathrm{C}$ prevent ESCC by inhibiting endogenous nitrosation (Lundell., 2010; Mao et al., 2011). We found that fruit and yellow or green vegetable consumption was significantly lower in ESCC patients than in control individuals in the Eastern Anatolian region. This discrepancy may be related to low socioeconomic level, ingrained nutritional habits, or difficulty in growing produce because of the long, harsh winter season.

A study evaluating risk factors in gastric cancer found that use of boiled yellow grease oil was an important risk factor in the Eastern Anatolian region (Dogan et al., 2009). We showed that consumption of boiled butter, mouldy cheese, and use of animal manure as a fuel source for cooking was significantly higher in ESCC patients than in 
Timur Koca et al

controls in rural areas. However, no significant correlation was observed between the consumption of herbed cheese or refrigerator use and ESCC.

Smoking and alcohol intake are major risk factors for ESCC in the United States of America, Western Europe, and other parts of the world (Thun et al., 1997, Pandeya et al., 2009). Alcohol and smoking synergistically promote oesophageal cancer development, and the risk ESCC is directly proportional to the number of cigarettes smoked and the amount of alcohol consumed daily (Tran et al., 2005; Vioque et al., 2008; Islami et al., 2011; Mao et al., 2011). In the present study, we found that smoking correlated with ESCC, whereas alcohol intake did not. The latter finding may reflect the limited alcohol intake of the local population because of religious beliefs. Others also found no correlation between alcohol consumption and ESCC.

Consumption of hot substances may increase oesophageal cancer risk by damaging oesophageal mucosa (Islami et al., 2009; Wu et al., 2009). A systemic review found that consumption of hot drinks increased risk in more than $50 \%$ of 59 clinical trials (Islami et al., 2009). In a case-control study performed in the northern part of Iran (which is very near the Eastern Anatolian region), the risk of ESCC was directly proportional to the amount of hot tea consumed and its temperature (Islami et al., 2009). Residents of the Eastern Anatolian region typically consume more tea and use 'sugar as a lump during tea drinking' than do residents of other regions. We observed a significant association between ESCC and daily consumption of 6 cups of tea or more. However, there was no association between sugar consumption during tea drinking and ESCC.

In conclusion, the present study identified regionspecific risk factors for ESCC. We found that the consumption of boiled yellow butter and mouldy cheese and the use of animal manure for food preparation as risks factors for ESCC in the Eastern Anatolian region. We suggest that more studies are required to potentially identify the carcinogenic substances that promote the development of ESCC in this region.

\section{References}

Amani F, Ahari SS, Akhghari L (2013). Epidemiology of esophageal cancer in Ardabil province during 2003-2011. Asian Pac J Cancer Prev, 14, 4177-80.

Andrici J, Eslick GD (2013). Mate consumption and the risk of esophageal squamous cell carcinoma: a meta-analysis. Dis Esophagus, 26, 807-16.

Blot WJ (1994). Esophageal cancer trends and risk factors. Semin Oncol, 21, 403-10.

De Stefani E, Deneo-Pellegrini H, Ronco AL, et al (2014). Diet patterns and risk of squamous cell oesophageal carcinoma: a case-control study in Uruguay. Asian Pac J Cancer Prev, 15, 2765-9.

Dogan NB, Timur K, Hakan D (2009). Dietary habits, hemographical, and socio-economical risk factors of the newly diagnosed gastric cancers in the Eastern Anatolia region of Turkey: An endemic upper gastrointestinal cancer region. Dig Dis Sci, 54, 2629-33.

Dubecz A, Solymosi N, Stadlhuber RJ, et al (2014). Does the incidence of adenocarcinoma of the esophagus and gastric cardia continue to rise in the twenty-first century?-a SEER database analysis. J Gastrointest Surg, 18, 124-9.

Enzinger PC, Mayer RJ(2003). Esophageal cancer. N Engl Med, 349, 2241-52.

Gammon MD, Schoenberg JB, Ahsan H, et al (1997). Tobacco, alcohol, and socioeconomic status and adenocarcinomas of the esophagus and gastric cardia. J Natl Cancer Inst, 89, 1277.

Hajmanoochehri F, Mohammadi N, Nasirian N, et al (2013). Patho-epidemiological features of esophageal and gastric cancers in an endemic region: a 20-year retrospective study. Asian Pac J Cancer Prev, 14, 3491-7.

Incarbone R, Bonavina L, Szachnowicz S, et al (2000). Rising incidence of esophageal adenocarcinoma in Western countries: is it possible to identify a population at risk? Dis Esophagus, 13, 275-8.

Islami F, Boffetta P, Ren JS, et al (2009). High-temperature beverages and foods and esophageal cancer risk-a systematic review. Int J Cancer, 125, 491.

Islami F, Pourshams A, Nasrollahzadeh D, et al (2009). Tea drinking habits and oesophageal cancer in a high risk area in northern Iran: population based case-control study. $B M J$, 338, 929.

Islami F, Fedirko V, Tramacere I, et al (2011). Alcohol driking and esophageal squamous cell carcinoma with focus on light-drinkers and never-smokers: asystematic review and meta-analysis. Int J Cancer, 129, 2473.

Jemal A, Siegel R, Ward E, et al (2009). Cancer stastistics, 2009. CA Cancer J Clin, 59, 225-49.

Jung SH, Gombojav B, Park EC, et al (2014). Population based study of the association between binge drinking and mortality from cancer of oropharynx and esophagus in Korean men: the Kangwha cohort study. Asian Pac J Cancer Prev, 15, 3675-9.

Kroep S, Lansdorp-Vogelaar I, Rubenstein JH, et al (2014). Comparing trends in esophageal adenocarcinoma incidence and lifestyle factors between the United States, Spain, and the netherlands. Am J Gastroenterol, 109, 336-43.

Lee KJ (2012). Obesity and functional gastrointestinal disorders. Korean J Gastroenterol, 59, 1-7.

Liu SZ, Wang B, Zhang F, et al (2013). Incidence, survival and prevalence of esophageal and gastric cancer in Linzhou city from 2003 to 2009. Asian Pac J Cancer Prev, 14, 6031-4.

Lundell LR (2010). Etiology and risk factors for esophageal carcinoma. Dig Dis, 28, 641-4.

Mao WM, Zheng WH, Ling ZQ (2011). Epidemiologic risk factors for esophageal cancer development. Asian Pac $J$ Cancer Prev, 12, 2461-6.

Moore MA, Eser S, Igisinov N, et al (2010). Cancer epidemiology and control in North-Western and central Asia-past, present and future. Asian Pac J Cancer Prev, 11, 17-32.

Mosavi-Jarrahi A, Ahmadi-Jouibari T, Najafi F, et al (2013). Estimation of esophageal cancer incidence in Tehran by log- linear method using population-based cancer registry data. Asian Pac J Cancer Prev, 14, 5367-70.

Pandeya N, Williams G, Green AC, et al (2009). Alcohol consumption and the risks of adenocarcinoma and squamous cell carcinoma of the esophagus. Gastroenterology, 136, 1215.

Pottern LM, Morris LE, Blot WJ, et al (1981). Esophageal cancer among black men in Washington.D.C.I. Alcohol, tobacco, and other risk factors. $J$ Natl Cancer Inst, 67, 777.

Sant M, Aareleid T, Berrino F, et al (2003). EUROCARE-3: Survival of cancer patients diagnosed 1990-94-results and commentary. Ann Oncol, 14, 61-118.

Sharma JD, Kalita M, Barman D, et al (2014). Patterns of 
Risk Factors for Oesophageal SCC in the Eastern Anatolia in Turkey Where Upper Gastrointestinal Cancers are Endemic upper aero-digestive tract cancers in Kamrup urban district of Assam:a retrospective study. Asian Pac J Cancer Prev, 15, 7267-70.

Tang L, Xu F, Zhang T, et al (2013). High temperature of food and beverage intake increases the risk of oesophageal cancer in Xinjiang, China. Asian Pac J Cancer Prev, 14, 5085-8.

Thun MJ, Peto R, Lopez AD, et al (1997). Alcohol consumption and mortality among middle-aged an elderly U.S. adults. $N$ Engl J Med, 337, 1705.

Tran GD, Sun XD, Abnet CC (2005). Prospective study of risk factors for esophageal and gastric cancers in the Linxian general population trial cohort in China. Int J Cancer, 113, 456-63.

Uyanikoglu A, Coskun M, Binici DN, et al (2011). Evaluation of gastroscopic and pathologic results Erzurum Region. Turkiye Klinikleri J Gastroenterohepatol, 18, 70-4.

Veugelers PJ, Porter GA, Guernsey DL, et al (2006). Obesity and lifestyle risk factors for gastroesophageal reflux disease, Barrett esophagus and esophageal adenocarcinoma. Dis Esophagus, 19, 321-8.

Vioque J, Barber X, Bolumar F, et al (2008). Esophageal cancer risk by type of alcohol drinking and smoking: a case-control study in Spain. BMC Cancer, 8, 221.

Weng Y, Fei B, He P, et al (2012). Glutathione-S-transferase T1 polymorphism is associated with esophageal cancer risk in Chinese Han population. Asian Pac J Cancer Prev, 13, 4403-7.

Wu M, Liu AM, Kampman E, et al (2009). Green tea drinking, high tea temperature and esophageal cancer in high- and lowrisk areas of Jiangsu Province, China: a population-based case-control study. Int J Cancer, 124, 1907. 